\title{
Bottleneck Pelayanan Nifas pada Upaya Penurunan Risiko Kejadian Kematian Ibu di Wilayah Dinas Kesehatan Kota Semarang
}

\author{
Ike Johan Prihatini*, Sri Achadi Nugraheni**, Sutopo Patria Jati** \\ *Universitas Pesantren Tinggi Darul 'Ulum \\ **Fakultas Kesehatan Masyarakat, Universitas Diponegoro \\ Email: ikejohan.undip@gmail.com
}

\section{ABSTRACT}

Maternal Mortality Rate in Semarang was ranked second highest in Central Java. The highest proportion of maternal deaths occurred during puerperium. That's indicates, there was a problem in a process of maternal health services during puerperium period in health facilities. This study was conducted to examine constraints on health systems that limit range of interventions or health services that were important for postpartum, bottlenecks related to postpartum services in Public Health Center (PHC), especially infrastructure, human resources, access to PHC, post partum visits (KF1 and KF3), as well as quality of post partum services on risk reduction of maternal mortality.

This case study used a qualitative approach. Data collection through interviews to five midwives as main informants, 5 midwives coordinator and 5 heads of PHC as informant triangulation. Data analsyis used content analysis method, then assigned priority bottleneck through MCUA (Multiple Criteria Utility Assessment) techniques. WHO's scale-up $B N A$ plan to analyze bottleneck causes.

Results showed, there was a bottleneck on childbirth services in PHC. The causes of bottleneck risk reduction efforts of maternal mortality incidence in puerperium period has never been analyzed workload of health personnel in
PHC, lack of monitoring and evaluation of an availability infrastructure facilities in PHC, there has not been regular training, especially on delivery until puerperium services, and PHC has not received more detailed and operational information about puerperium. Semarang Public Health Office (Dinas Kesehatan Kota Semarang) needs to conduct periodic monitoring and evaluation implementation of postpartum services and improve quality of childbirth services in $\mathrm{PHC}$.

Keywords: Bottleneck analysis, health services, post-partum, Primary Health Care, Puskesmas, Maternal Mortality Rate

\section{PENDAHULUAN}

AKI di Jawa Tengah sampai tahun 2016 masih tergolong tinggi dan menduduki urutan kedua sebagai propinsi penyumbang AKI terbanyak di Indonesia. Pada kurun waktu lima tahun terakhir, AKI di Jawa Tengah terus mengalami peningkatan, pada tahun 2011 terdapat 668 kasus, tahun 2012 terdapat 675 kasus, tahun 2013 tercatat 668 kasus, 2014 tercatat 711 kasus, tahun 2015 tercatat 619 kasus. AKI di Jawa Tengah tahun 2015 paling banyak terjadi di Kabupaten Brebes dengan 51 kasus, kemudian Kota Semarang 35 kasus, Kabupaten Grobogan dengan 32 kasus, Kabupaten Pemalang dengan 32 kasus dan Kabupaten Tegal 
dengan 31 kasus. Penyebab kejadian kematian ibu di Kota Semarang, yaitu eklampsia (34\%), perdarahan (28\%), penyakit lain $(26 \%)$, dan lain-lain sebesar $12 \%{ }^{1}$

Hal ini mengindikasikan bahwa terdapat masalah dalam proses pelayanan kesehatan ibu pada masa nifas di fasilitas kesehatan. Hasil analisis bottleneck dapat menggambarkan sumbatan pada keseluruhan sistem pelayanan kesehatan. ${ }^{2}$ Pada upaya penurunan risiko kejadian kematian ibu, analisis bottleneck secara khusus dilakukan untuk menguraikan intervensi pelayanan kesehatan yang termasuk dalam 66 intervensi yang direkomendasikan oleh The Lancet sebagai intervensi dengan efikasi yang tinggi untuk mengatasi penyebab kejadian kematian ibu. $^{3}$

Penelitian ini dilakukan untuk melihat kendala pada sistem kesehatan yang membatasi cakupan intervensi atau pelayanan kesehatan yang penting untuk ibu nifas dan bottleneck yang berkaitan dengan pelayanan nifas di fasilitas kesehatan dasar terutama dukungan sarana prasarana, SDM, keterjangkauan akses lokasi Puskesmas, kunjungan nifas KF1 dan KF3, serta kualitas pelayanan nifas pada upaya penurunan risiko kejadian kematian ibu.

\section{METODE PENELITIAN}

Jenis penelitian yang digunakan dalam penelitian ini adalah studi kasus dengan pendekatan kualitatif. Penelitian dilaksanakan pada bulan April 2016 sampai dengan September tahun 2017 yang berlokasi di Wilayah Dinas Kesehatan Kota Semarang Propinsi Jawa Tengah. Dimana observasi dilaksanakan di 29 Puskesmas. Pengkajian melalui wawancara mendalam dilaksanakan di 5 Puskesmas yang terdapat kejadian kematian ibu pada tahun 2015 dan 2016, diantaranya Puskesmas Poncol, Bandarharjo, Tlogosari Kulon, Halmahera, dan Purwoyoso.

Pengumpulan data dilakukan sekaligus pada satu kali kegiatan pengamatan, melalui wawancara mendalam kepada 5 bidan pelaksana sebagai informan utama, 5 bidan koordinator dan 5 kepala puskesmas sebagai informan triangulasi. Kriteria inklusi informan utama yaitu 1) Bidan Pelaksana di Puskesmas yang direkomendasikan oleh Bidan Koordinator; 2) Bidan Pelaksana yang memiliki tanggung jawab di wilayah yang terdapat kejadian kematian ibu maternal pada tahun 2015-2016; 3) Mampu berkomunikasi dengan baik; 4) Menyatakan bersedia untuk menjadi informan. Pengumpulan data dengan cara wawancara mendalam, observasi dengan mengggunakan daftar checklist dan telaah dokumen.

Data dianalisis menggunakan metode content analysis, selanjutnya ditetapkan prioritas bottleneck melalui teknik MCUA (Multiple Criteria Utility Assessment). Penentuan penyebab terjadinya bottleneck melalui BNA scale-up plan dari WHO untuk menganalisis penyebab bottleneck melalui data observasi dan wawancara mendalam.

\section{HASIL DAN PEMBAHASAN}

Menurut WHO, pada $2013 \quad 80 \%$ penyebab kematian maternal adalah komplikasi obstetri diantaranya perdarahan, sepsis, distosia, eklampsia atau preeklampsia, dan lain-lain. ${ }^{4,5}$ Sekitar 16$33 \%$ penyebab kematian maternal karena keterbatasan kemampuan dan keterampilan penolong pelayanan maternal.,7 Bidan perlu memberikan konseling kepada pasien mengenai kondisi kegawatdaruratan, risiko yang dapat terjadi sehingga dapat mempersiapkan pertolongan segera kepada pasien. ${ }^{8}$ Sosialisasi pelatihan dan pemenuhan ketersediaan peralatan kesehatan bagi bidan merupakan langkah efektif untuk penyelamatan ibu dan bayi. ${ }^{9}$

Perlu diberikan edukasi dan pelatihan bagi bidan agar dapat memberikan konseling, informasi dan edukasi yang tepat dan sesuai standar bagi ibu post partum untuk menurunkan risiko komplikasi dan kematian ibu. ${ }^{10}$ Beberapa wanita kurang memperhatikan kondisi 
kesehatannya setelah melalui proses persalinannya, kurang peka mengenai tanda dan gejala abnormal hingga gawat darurat. $^{11}$

Pada penelitian ini dilaksanakan observasi dan wawancara mendalam terhadap dua komponen besar yaitu supply yang terdiri dari ketersediaan sarana prasarana, peralatan dan obat, SDM yang dimiliki di sistem kesehatan, dan akses ke fasilitas kesehatan. Sisi yang kedua adalah sisi demand yang terdiri dari utilisasi pelayanan kesehatan, keberlangsungan penggunaan oleh masyarakat dan kualitas pelayanan yang diterima masyarakat. Hasil observasi dan wawancara mendalam, sebagai berikut:

1. Bottleneck dari Aspek Supplies pelayanan nifas

Informasi yang dikaji melalui wawancara mendalam dengan informan utama dan informan triangulasi tentang ketersediaan sarana dan prasarana pelayanan nifas di Puskesmas adalah mengenai ketersediaan sarana prasarana medis, sarana prasarana non medis, sarana prasarana rujukan, sarana prasarana penanganan emergency maternal, sarana prasarana promosi kesehatan, sarana prasarana promosi kesehatan pelayanan nifas, dan kendala di bidang ketersediaan fasilitas dan peralatan. Bottleneck dari Aspek Supplies pelayanan nifas, sebagian besar diakibatkan karena kurangnya ketersediaan sarana dan prasarana medis pelayanan nifas.

Kendala yang dialami yaitu kelengkapan peralatan medis yang ada di ruang pelayanan kebidanan masih diperlukan penambahan sesuai standar untuk mendukung pelayanan yang berkualitas dan keterbatasan ruangan BKIA, dibutuhkan ruangan terpisah untuk pemeriksaan ibu dan pemeriksaan bayi/balita.

2. Bottleneck dari Aspek Staff pelayanan nifas

Informasi yang dikaji melalui wawancara mendalam dengan informan utama dan informan triangulasi tentang staff (Sumber Daya Manusia) adalah kuantitas yaitu dokter dan bidan yang ada, latar belakang pendidikan, pelatihan Asuhan Persalinan Normal (APN), pelatihan penanganan emergensi, upaya dalam meningkatkan pengetahuan dan keterampilan dalam pelayanan nifas, bimbingan dalam melaksanakan pelayanan nifas, monitoring dan evaluasi pelayanan nifas yang telah dilaksanakan, penanganan kegawatdaruratan, pelaksanaan kunjungan nifas (home care visit), tunjangan pegawai dalam pelayanan kunjungan nifas (home care visit), kendala di bidang sumber daya manusia, dan upaya dalam menangani kendala di bidang sumber daya manusia di Puskesmas. Bottleneck dari Aspek Staff pelayanan nifas, sebagian besar karena kurangnya jumlah bidan.

Kendala yang dialami yaitu jumlah tenaga kesehatan di Kota Semarang masih kurang, namun ada beberapa Puskesmas yang kelebihan tenaga kesehatan, hal tersebut menunjukkan bahwa penyebaran tenaga kesehatan di Kota Semarang belum merata.

Sesuai dengan konsep Health for All bahwa dalam masyarakat, rasio 1 bidan bertanggung jawab terhadap 1000 penduduk, sedangkan di Puskesmas di Kota Semarang rata-rata memiliki wilayah kerja 3 sampai 4 kelurahan, estimasi penduduk untuk 1 wilayah kelurahan adalah 3000-5000 penduduk, dengan demikian estimasi 3 wilayah tersebut penduduk berjumlah 9000-15000 penduduk, sehingga bidan yang ada di wilayah kerja tersebut minimal ada 9 orang. ${ }^{12}$ Perlu dilaksanakan analisis kinerja, analisis beban kerja untuk mengetahui kebutuhan bidan di Puskesmas, agar dapat tercapai pelaksanaan pelayanan yang optimal, misalnya dengan Analisis Beban Kerja (ABK) ABK, Work Load Indicator Staff Need (WISN), atau dengan metode analisis lain. ${ }^{13}$ Tingginya beban kerja tenaga kesehatan akan meningkatkan tingkat stress dan meningkatkan risiko 
terjadinya kesalahan dalam pertolongan medis dikarenakan human error. ${ }^{14}$

\section{Bottleneck dari Aspek Access pelayanan nifas}

Informasi yang dikaji melalui wawancara mendalam dengan informan utama dan informan triangulasi tentang keterjangkauan akses lokasi pelayanan kesehatan di Puskesmas adalah sarana transportasi untuk menuju Puskesmas, sarana akses jalan untuk menuju ke Puskesmas, akses SDM dalam melakukan kunjungan nifas (home care visit), kendala di bidang keterjangkauan (akses) di Puskesmas, proses rujukan di Puskesmas, dan sistem rujukan dari Puskesmas ke Rumah Sakit.

Bottleneck dari Aspek Access pelayanan nifas, sebagian besar karena jarak tempuh yang cukup jauh (lebih dari 3 $\mathrm{km}$ ) dan waktu tempuh yang cukup lama (lebih dari 30 menit).

Grafik bottleneck dari aspek access menunjukkan semua Puskesmas memiliki bottleneck minor pada aspek access dengan skor $66,66 \%$ di Puskesmas Wilayah Dinas Kesehatan Kota Semarang. Hal ini terjadi, karena rata-rata jarak tempuh Puskesmas dengan masyarakat lebih dari $3 \mathrm{~km}$, ratarata waktu tempuh Puskesmas dengan masyarakat lebih dari 30 menit, namun sudah tersedia Rumah Sakit yang dapat diakses Puskesmas dalam waktu maksimal 2 jam perjalanan (untuk Puskesmas PONED) atau 30 menit (untuk Puskesmas non-PONED). Bottleneck minor pada aspek access terjadi karena wilayah kerja Puskesmas yang luas, rata-rata Puskesmas memiliki wilayah kerja 3 sampai 4 kelurahan, dan rasio jumlah penduduk setempat tidak seimbang dengan jumlah tenaga kesehatan (aspek staff).

\section{Bottleneck dari Aspek Utilizations pelayanan nifas}

Informasi yang dikaji melalui wawancara mendalam dengan informan utama dan informan triangulasi tentang kunjungan nifas pertama kali (KF1) di
Puskesmas adalah respon masyarakat terhadap pelayanan nifas, dan kendala terkait cakupan kunjungan nifas pertama kali (KF1).

Bottleneck dari Aspek Utilizations pelayanan nifas terkait dengan komponen penggunaan (utilisasi) oleh masyarakat di Puskesmas, sebagian besar karena pengetahuan masyarakat mengenai pelayanan dan kebutuhan ibu hamil, bersalin dan nifas sangat minim.

Hal ini menunjukkan bahwa pengetahuan beberapa ibu nifas mengenai pelayanan dan kebutuhan ibu hamil, bersalin dan nifas sangat minim. Perlu komitmen untuk meningkatkan pengetahuan kesehatan masyarakat sehingga demand untuk mendapatkan pelayanan kesehatan di Puskesmas dapat meningkat. Pelayanan masa nifas di Puskesmas terbantu karena adanya kunjungan bidan dan pendampingan ibu hamil oleh Gasurkes KIA dan kader kesehatan.

\section{Bottleneck dari Aspek Continuity pelayanan nifas}

Informasi yang dikaji melalui wawancara mendalam dengan informan utama dan informan triangulasi tentang kunjungan nifas berkelanjutan di Puskesmas adalah respon masyarakat terhadap pelayanan kunjungan nifas kedua dan ketiga, pelayanan kunjungan ulang yang diberikan oleh tenaga kesehatan, dan kendala terkait cakupan kunjungan nifas lengkap (KF2 dan KF3) di Puskesmas.

Bottleneck dari Aspek Continuity pelayanan nifas terkait dengan komponen penggunaan berkelanjutan (kontinuitas) pelayanan kunjungan nifas oleh masyarakat di Puskesmas, sebagian besar karena pengetahuan masyarakat mengenai pelayanan dan kebutuhan ibu hamil, bersalin dan nifas sangat minim.

Cakupan kunjungan nifas untuk Puskesmas yang belum mencapai target dikarenakan pencatatan dan pelaporan kunjungan nifas yang belum maksimal, banyak ibu nifas tidak melakukan 
kunjungan nifas ke fasilitas kesehatan, karena kurangnya pengetahuan ibu tentang pentingnya kunjungan nifas, tenaga Puskesmas yang kurang memanfaatkan dana BOK dengan maksimal, dan Gsurkes yang hanya ditargetkan melaksanakan kunjungan nifas tiga kali, baru mencapai rata-rata 2 kali. Perlu komitmen untuk meningkatkan pengetahuan kesehatan masyarakat sehingga demand untuk mendapatkan pelayanan kesehatan di Puskesmas dapat meningkat. Pelayanan masa nifas di Puskesmas terbantu karena adanya kunjungan bidan dan pendampingan ibu hamil oleh Gasurkes KIA dan kader kesehatan.

Pemberian konseling, informasi dan edukasi dan health education kepada pasien mengenai tanda gejala dan penanganan kegawatdaruratan masa nifas sebaiknya sejak masa kehamilan dan diingatkan kembali pada saat pasien melakukan kunjungan nifas. ${ }^{15}$ Namun belum semua bidan melaksanakan proses discharge education yang tepat pada ibu post partum. Padahal discharge education merupakan proses kritis persiapan pasien untuk kembali ke rumah yang masih harus mendapat pemantauan dan pemeriksaan kondisi kesehatannya di masa nifas.

6ottleneck dari Aspek Quality
pelayanan nifas
Informasi yang dikaji melalui wawancara mendalam dengan informan utama dan informan triangulasi tentang kualitas pelayanan nifas di Puskesmas adalah kualitas pelayanan dan upaya yang perlu dilaksanakan Puskesmas agar dapat memberikan pelayanan masa nifas berkualitas.

Bottleneck dari Aspek Quality pelayanan nifas menunjukkan adanya keterkaitan antara kualitas pelayanan dengan aspek supplies, staff, access, utilizations dan continuity. Puskesmas yang memiliki bottleneck pada kualitas pelayanan masa nifas, memiliki bottleneck pada aspek supplies, staff, access, utilizations dan continuity.
Kendala pada kualitas pelayanan nifas di Puskesmas karena: Keterbatasan jumlah SDM bidan, bidan double job dengan tugas struktural, dan terdapat pasien post partum masih ada keluhan namun sudah dipulangkan dari RS.

Analisis bottleneck menunjukkan adanya keterkaitan antara kualitas pelayanan dengan aspek supplies, staff, access, utilizations dan continuity. Puskesmas yang memiliki kualitas pelayanan masa nifas yang baik, telah memiliki supplies, staff, access, utilizations dan continuity yang baik. Sebaliknya, Puskesmas yang memiliki bottleneck pada kualitas pelayanan masa nifas, memiliki bottleneck pada supplies, staff, access, utilizations dan continuity.

7. Analisis penyebab terjadinya bottleneck

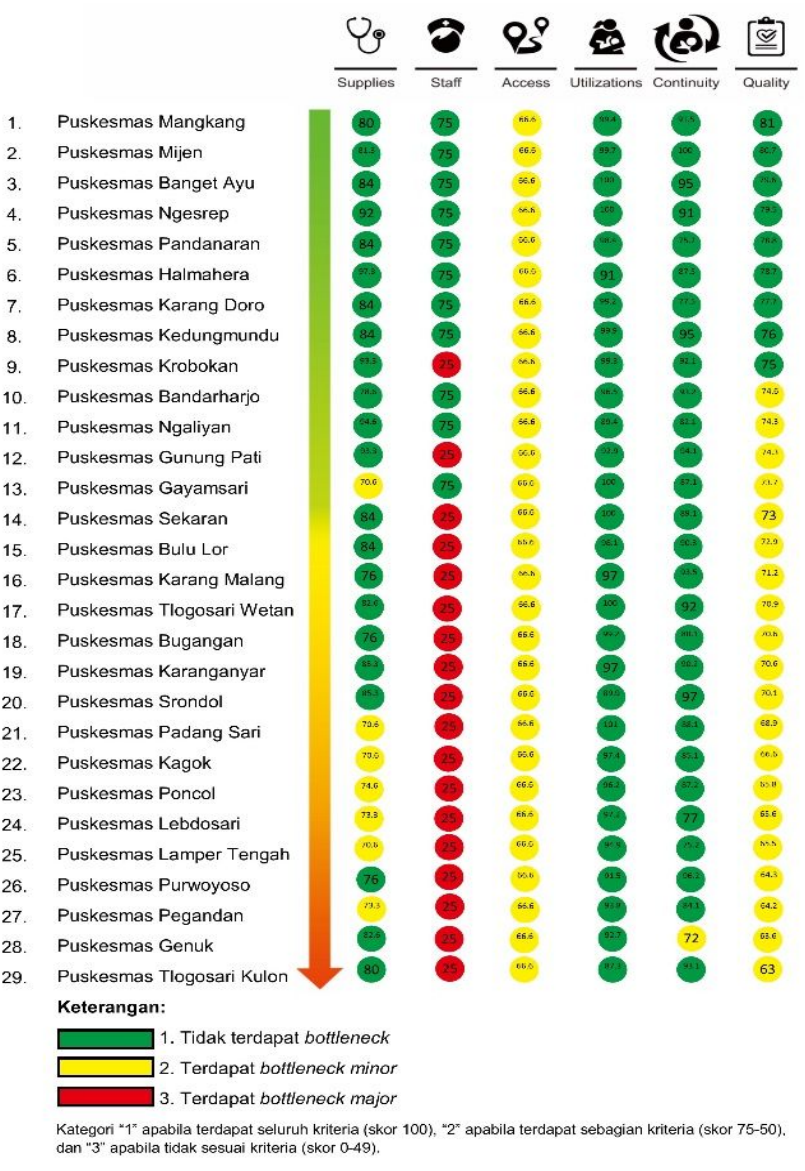

Gambar 2. Hasil Analisis Bottleneck 29

Puskesmas di Wilayah Dinas Kesehatan Kota Semarang 
Mengadaptasi grafik bottleneck model Tanahashi, gambar 2 menunjukkan identifikasi bottleneck dalam pelayanan nifas pada upaya penurunan risiko kejadian kematian ibu di 29 Puskesmas Wilayah Dinas Kesehatan Kota Semarang. Kategori bottleneck dari gambar di atas berdasarkan Facility Assessment Team (FIT), tidak terdapat Bottleneck dengan warna hijau apabila terdapat seluruh kriteria (skor 100), bottleneck minor dengan warna kuning apabila terdapat sebagian kriteria (skor 7550), dan bottleneck major dengan warna merah apabila tidak sesuai kriteria (skor 049).

FIT merupakan sistem scoring yang dapat menggambarkan ketersediaan minimal di fasilitas pelayanan kesehatan dasar. Menggunakan sistem scoring FIT nampak Puskesmas Mangkang, Mijen dan Bangetayu memiliki nilai tertinggi dengan hasil area hijau (tidak terdapat bottleneck). Puskesmas dengan skor FIT terendah yaitu Puskesmas Pegandan, Genuk dan Tlogosari Kulon.

Analisis penyebab terjadinya bottleneck upaya penurunan risiko kejadian kematian ibu pada masa nifas yaitu belum pernah dilaksanakan analisis beban kerja tenaga kesehatan di Puskesmas, kurangnya monitoring evaluasi mengenai ketersediaan sarana prasarana di Puskesmas, belum terdapat pelatihan secara rutin, khususnya pada pelayanan pertolongan persalinan sampai dengan masa nifas, dan masyarakat belum mendapatkan informasi yang lebih rinci dan operasional tentang masa nifas sehingga pengetahuan ibu tentang masa nifas belum banyak meningkat.

Puskesmas Mangkang memiliki nilai tertinggi dengan hasil area hijau (tidak terdapat bottleneck) pada aspek supplies, staff, utilizations dan continuity. Puskesmas Mangkang memiliki ketersediaan sarana prasarana dengan skor $80 \%$, memiliki ketersediaan sumber daya manusia dengan skor $75 \%$ yaitu 3 dokter, 6 bidan, bidan terlatih APN dalam 5 tahun terakhir, dan bidan terlatih penanganan emergensi, memiliki cakupan kunjungan nifas pertama 99,4\%, cakupan kunjungan nifas ketiga 91,57\%, dan kualitas pelayanan nifas dengan skor $81,07 \%$. Terdapat kendala akses pelayanan nifas yaitu cakupan wilayah yang cukup luas, sehingga menunjukkan skor pada aspek access $66,66 \%$.

Ketersediaan staff di Puskesmas Mangkang telah sesuai dengan Peraturan Menteri Kesehatan Nomor 75 Tahun 2014 tentang Pusat Kesehatan Masyarakat, Puskesmas rawat jalan memiliki minimal 2 dokter dan 4 bidan. Berdasarkan hasil analisis data Autopsy Verbal Maternal (OVM), tidak terdapat kejadian kematian ibu pada tahun 2015-2016 di Puskesmas Mangkang. Puskesmas dengan skor FIT terendah yaitu Puskesmas Pegandan, Genuk, dan Tlogosari Kulon dengan hasil area kuning (terdapat bottleneck minor) dan area merah (terdapat bottleneck major).

Puskesmas Tlogosari Kulon memiliki bottleneck pada aspek staff, access dan quality. Hal ini menunjukkan bahwa Puskesmas yang memiliki kualitas pelayanan masa nifas yang buruk, memiliki supplies, staff, access, utilizations dan continuity yang masih buruk. Berdasarkan hasil observasi, ketersediaan sarana prasarana dengan skor $80 \%$, memiliki ketersediaan sumber daya manusia dengan skor 25\% (bottleneck major) yaitu 3 dokter, 7 bidan, bidan belum seluruhnya terlatih APN dalam 5 tahun terakhir, dan bidan belum seluruhnya terlatih penanganan emergensi, memiliki cakupan kunjungan nifas pertama $87,3 \%$, cakupan kunjungan nifas ketiga 93,1\%, dan kualitas pelayanan di Puskesmas Tlogosari Kulon memiliki skor 63,04\% (bottleneck minor) sesuai standar Need Assesment Safe Motherhood dan Standard Based Management and Recognition Pelayanan Kesehatan Ibu dan Anak di Puskesmas/Puskesmas PONED.

Berdasarkan hasil analisis data Autopsy Verbal Maternal (OVM), terdapat kejadian kematian ibu pada masa nifas 3 orang pada tahun 2015 dan 2 orang pada tahun 2016 di Puskesmas Tlogosari Kulon. 
Hal ini menunjukkan bahwa pemenuhan sarana prasarana, tenaga kesehatan dan pelayanan berkualitas dalam pertolongan atau pelayanan pemeriksaan kehamilan, persalinan, BBL dan masa nifas menjadi strategi yang efektif dalam meningkatkan kualitas dan menurunkan kejadian kematian ibu dan anak.

Hal ini menunjukkan bahwa pemenuhan sarana prasarana, tenaga kesehatan dan pelayanan berkualitas dalam pertolongan atau pelayanan pemeriksaan kehamilan, persalinan, BBL dan masa nifas menjadi strategi yang efektif dalam meningkatkan kualitas dan menurunkan kejadian kematian ibu dan anak.

Identifikasi bottleneck yaitu:

a. Sumber Daya Manusia (SDM) bidan di Puskesmas masih kurang

b. Belum tersedianya sarana prasarana yang lengkap

c. Wilayah kerja Puskesmas terlalu luas (4 Kelurahan atau lebih)

d. Pengetahuan dan kontribusi masyarakat dalam pelayanan dan kebutuhan ibu hamil, bersalin dan nifas sangat minim

e. Pelatihan dan update informasi bagi bidan di Puskesmas masih kurang

Pada penentuan identifikasi bottleneck di atas, ditetapkan prioritas bottleneck dengan menggunakan teknik Multiple Criteria Utility Assessment (MCUA). Kriteria yang digunakan adalah urgensi, dan relevansi.

Hasil berdasarkan teknik Multiple Criteria Utility Assessment (MCUA) ditetapkan prioritas bottleneck, sebagai berikut:

1) Sumber Daya Manusia (SDM) bidan di Puskesmas masih kurang

2) Belum tersedianya sarana prasarana yang lengkap

3) Pelatihan dan update informasi bagi bidan di Puskesmas masih kurang

4 ) Pengetahuan dan kontribusi masyarakat dalam pelayanan dan kebutuhan ibu hamil, bersalin dan nifas sangat minim

Rekomendasi strategi penyelesaian

bottleneck untuk menurunkan risiko kejadian kematian ibu di Wilayah Dinas
Kesehatan Kota Semarang yaitu melalui menyediakan Sumber Daya Manusia (SDM) bidan di Puskesmas yang memadai, menyediakan sarana prasarana yang lengkap, meningkatkan kemampuan dan keterampilan bidan di Puskesmas dalam memberikan pelayanan masa nifas, meningkatkan pengetahuan dan kontribusi masyarakat dalam pelayanan dan kebutuhan ibu hamil, bersalin dan nifas yang mana saat ini masih sangat minim.

\section{KESIMPULAN}

Penyebab terjadinya bottleneck upaya penurunan risiko kejadian kematian ibu pada masa nifas yaitu belum pernah dilaksanakan analisis beban kerja tenaga kesehatan di Puskesmas, kurangnya monitoring evaluasi mengenai ketersediaan sarana prasarana di Puskesmas, belum terdapat pelatihan secara rutin, khususnya pada pelayanan pertolongan persalinan sampai dengan masa nifas, dan masyarakat belum mendapatkan informasi yang lebih rinci dan operasional tentang masa nifas sehingga pengetahuan ibu tentang masa nifas belum banyak meningkat dan menimbulkan kesadaran ibu untuk melakukannya.

Dinas Kesehatan, perlu menganalisis kembali beban kerja tenaga kesehatan di Puskesmas, meningkatkan pengetahuan dan keterampilan bidan di Puskesmas melalui pelatihan secara berkala, melaksanakan monitoring, evaluasi, secara berkala, menyusun sistem rujukan yang terstruktur untuk mempersiapkan pertolongan emergensi bagi pasien, mempertahankan upaya pendampingan ibu hamil oleh Gasurkes KIA dan kader kesehatan, meningkatkan upaya promotif Keluarga Berencana (KB), dan melaksanakan advokasi dengan Pemerintah Daerah untuk memberikan dukungan pada program penyelamatan ibu dan anak.

\section{DAFTAR PUSTAKA}

1. Dinas Kesehatan Provinsi Jawa Tengah. Profil Dinas Kesehatan 
Provinsi Jawa Tengah. Semarang: Dinas Kesehatan Provinsi Jawa Tengah, 2015.

2. O' Connell T, Sharkey A. Reaching universal health coverage: using a modified Tanahashi model subnationally to attain equitable and effective coverage. New York, 2013.

3. Kurniawan MF, Marthias T, Purwaningrum DN, et al. Perencanaan Berbasis Bukti Untuk Menjawab Kebutuhan Kesehatan Anak Dan Jaminan Sosial Bidang Kesehatan: Studi Kasus Tasikmalaya Dan Jayawijaya. In: Child Poverty and Social Protection Conference. Jakarta: Child Poverty and Social Protection Conference, https://www.neliti.com/id/publications /586/perencanaan-berbasis-buktiuntuk-menjawab-kebutuhankesehatan-anak-dan-jaminan-s (2013).

4. World Health Organization. Pregnancy, childbirth, postpartum, and newborn care. Maternal, Child, and Adolescent, http://www.who.int/maternal_child_ad olescent/documents/imca-essentialpractice-guide/en/ (2015, accessed 13 February 2017).

5. Owens P, Mutter R, Stocks C. Mental health and substance abuse related emergency department visits among adults in 2007. Rockville, http://www.hcup-

us.ahrq.gov/reports/stratbricfs/sb92.pd $\mathrm{f}(2010)$.

6. World Health Organization. WHO Air quality guidelines global update 2005 . Report on a Working Group Meeting, http://www.cure.who.int/_data/assets/p df_file/0008/147851/E87950.pdf (2005, accessed 13 February 2017).

7. Slade EP, Dixon LB, Semmel S. Trends in the duration of emergency department visits, 2001-2006. Psychiatr Serv 2010; 61: 871-884.

8. Revolutionary Government of Zanzibar. The National Road Map Strategic Plan to Accelerate Reduction of Maternal, Newborn, and Child Deaths in Zanzibar, www.afro.who.int (2015, accessed 13 February 2017).

9. Cacko JA, Cissé K, Pambè MW, et al. Evaluation of the implementation and effects of an obstetric kit used in the Adamawa region of Cameroon. Int $J$ Gynecol Obstet 2016; 135: 103-106.

10. Suplee PD, Kleppel L, Bingham D. Discharge Education on Maternal Morbidity and Mortality Provided by Nurses to Women in the Postpartum Period. JOGNN - J Obstet Gynecol Neonatal Nurs 2016; 45: 894-904.

11. Bowman KG. Postpartum learning needs. JOGNN - J Obstet Gynecol Neonatal Nurs 2005; 34: 438-443.

12. Kementerian Pendayagunaan Aparatur Negara. Keputusan Menteri Pendayagunaan Aparatur Negara Nomor: $\quad$ Kep/75/M.Pan/7/2004 Tentang Pedoman Perhitungan Kebutuhan Pegawai Berdasarkan Beban Kerja Dalam Rangka Penyusunan Formasi Pegawai Negeri Sipil. Kep/75/M.Pan/7/2004, Indonesia, 2004.

13. Meidiawati C. Analisis beban kerja untuk menentukan kebutuhan tenaga perawat dengan metode Workload Indicators of Staffing Need (WISN) di Instalasi Rawat Inap Flamboyan Rumah Sakit Tugu Ibu tahun 2012. Universitas Indonesia, http://lib.ui.ac.id/file?file=pdf/abstrak20329188.pdf (2012).

14. Anna K, Efendi F. Kajian SDM Kesehatan di Indonesia. Jakarta: Salemba Medika, 2012.

15. Kassebaum NJ, Bertozzi-Villa A, Coggeshall MS, et al. Global, regional, and national levels and causes of maternal mortality during 1990-2013: A systematic analysis for the Global Burden of Disease Study 2013. Lancet 2014; 348: 980-1004. 